\title{
Serum levels of L1-0RF1p and airflow limitation
}

\author{
To the Editor:
}

LINE-1 (long interspersed nuclear element-1) is a group of polymorphic DNA sequences in the human genome that mobilise via RNA binding proteins, reverse transcriptase and endonuclease to alter the host genome via mutational insertions, chromosomal rearrangements and reprogramming of gene expression (reviewed by Ramos et al. [1]). Full-length LINE-1 sequences encode two proteins: L1-ORF1p, a 40-kDa protein with nucleic acid binding activity; and L1-ORF2p, a 150-kDa protein with endonuclease and reverse transcriptase activities. The activity of LINE-1 is repressed in somatic tissues via DNA methylation and covalent protein modifications, and reactivated by displacement of retinoblastoma-associated proteins from the regulatory region [2]. Recent studies in our laboratory have implicated LINE-1 as a master regulator of human bronchial epithelial cell phenotypes in experimental in vitro and in vivo models [3].

Methylation profiles of LINE-1 have been linked to cancer and other chronic diseases related to smoking [4], and a previous report from the Normative Aging Study [5] found LINE-1 hypomethylation to be associated with faster decline of both forced expiratory volume in $1 \mathrm{~s}\left(\mathrm{FEV}_{1}\right)$ and forced vital capacity (FVC) among 301 adult participants, the majority of whom were former smokers. However, it is not yet known if the expression of proteins encoded by LINE-1 is upregulated in cases of impaired lung function or COPD. The aim of this study was to determine the association between circulating levels of L1-ORF1p, lung function and airflow limitation in the Tucson Epidemiological Study of Airway Obstructive Disease (TESAOD).

TESAOD is a population-based cohort study of non-Hispanic white households in Tucson, AZ, USA [6]. Briefly, at enrolment in 1972-1973, participants completed standardised respiratory questionnaires and spirometric lung function tests according to methods previously described [7]. For the present study, we used data from the enrolment survey on $\mathrm{FEV}_{1}, \mathrm{FVC}$ and $\mathrm{FEV}_{1} / \mathrm{FVC}$. Percent predicted values for lung function indices were computed using reference equations generated from the same population by KNUDSON et al. [8]. Airflow limitation was defined both as a fixed cut-off of $\mathrm{FEV}_{1} / \mathrm{FVC}<70 \%$ and, to control for differences by sex and age, as $\mathrm{FEV}_{1} / \mathrm{FVC}$ below the lower limit of normal (LLN) [9].

Blood samples were collected at enrolment, processed into serum and cryopreserved at $-80^{\circ} \mathrm{C}$. For this study, we selected a subgroup of 427 participants who, at enrolment, were 35-70 years old, completed questionnaires and lung function tests, and had sufficient serum volumes. Serum concentrations of L1-ORF1p were measured using an ELISA. A custom polyclonal anti-human L1-ORF1p antibody was produced by New England Peptide LLC (Gardner, MA, USA). The antigen peptide MGKKQNRKTGNSKTQ used to generate a rabbit polyclonal does not match the murine ORF1p amino acid sequence. The specificity of the antibody was validated using several criteria including a single band of the expected molecular weight by Western blotting, specific knockdown of signal intensity using small interfering RNAs and high reproducibility. Biochemical validation of the anti-L1-ORF1p has been described previously [3]. The antibody was diluted one in 1000 for use in all experiments. Goat anti-rabbit whole-molecule immunoglobulin conjugated to horseradish peroxidase (Sigma-Aldrich, St Louis, MO, USA) was used as secondary antibody. Serum samples were analysed on six different runs using 96-well microplates.

@ERSpublications

In a population-based study, higher circulating levels of L1-ORF1p were associated with lower lung function levels and increased risk for airflow limitation among former smokers http://bit.ly/ $2 \mathrm{ZEIjNv}$

Cite this article as: Guerra S, Vasquez MM, Bojang P Jr, et al. Serum levels of L1-ORF1p and airflow limitation. ERJ Open Res 2019; 5: 00247-2018 [https://doi.org/10.1183/23120541.00247-2018]. 
In statistical analyses, we tested the association of L1-ORF1p with lung function indices and with the presence of airflow limitation using L1-ORF1p levels both on a continuous scale (after standardisation so that estimates would represent effects by 1-SD increase) and as quartiles to evaluate nonlinear effects. Because plate effects explained up to $20 \%$ of the variability in L1-ORF1p levels, we used mixed-effects models with plate number fitted as a random effect to control for interplate variability. Random-effects models were used for analyses of $\mathrm{FEV}_{1}, \mathrm{FVC}$ and $\mathrm{FEV}_{1} / \mathrm{FVC}$, and multilevel mixed-effects logistic regression models were used for analyses on airflow limitation. Models were adjusted for sex, age, body mass index (BMI), smoking status and pack-years because these factors may be related to both L1-ORF1p and lung function and, in turn, act as confounders.

The 427 participants had a mean age of 55 years and a mean BMI of $24.8 \mathrm{~kg} \cdot \mathrm{m}^{-2}$. They were largely represented by females ( 284 out of $427,67 \%$ ) and smokers ( 249 out of $427,58 \%$ ), with a mean value of 30 pack-years among smokers. 35 participants (8\%) reported physician-confirmed active asthma. The mean \pm SD L1-ORF1p serum concentration was $46 \pm 26 \mathrm{ng} \cdot \mathrm{mL}^{-1}$. L1-ORF1p levels were higher in males than females (51 versus $\left.44 \mathrm{ng} \cdot \mathrm{mL}^{-1}, \mathrm{p}=0.01\right)$. Smokers had borderline higher L1-ORF1p levels than never-smokers (48 versus $\left.44 \mathrm{ng} \cdot \mathrm{mL}^{-1}, \mathrm{p}=0.09\right)$, with former $\left(50 \mathrm{ng} \cdot \mathrm{mL}^{-1}\right)$ rather than current (46 ng. $\mathrm{mL}^{-1}$ ) smokers having the highest levels. Although participants with active asthma tended to have higher levels than participants without active asthma (52 versus $46 \mathrm{ng} \cdot \mathrm{mL}^{-1}, \mathrm{p}=0.16$ ), this association was not statistically significant. L1-ORF1p levels were not associated with age or BMI.

Table 1 summarises the results of analyses of lung function. In adjusted models of the total study population, we did not find significant associations between L1-ORF1p serum levels and any of the lung function indices, although a trend was observed for airflow limitation. When analyses were stratified by smoking status, however, we observed consistent associations among smokers, which were largely driven by the group of former smokers. In this group, each 1-SD increase in L1-ORF1p was associated with a reduction of $7.1 \%$ in $\mathrm{FEV}_{1}(\mathrm{p}<0.001), 5.5 \%$ in $\mathrm{FVC}(\mathrm{p}=0.001)$ and $2.3 \%$ in $\mathrm{FEV}_{1} / \mathrm{FVC}(\mathrm{p}=0.009)$, and with a two-fold increased risk of airflow limitation ( $\mathrm{p}=0.014$ for $\mathrm{FEV}_{1} / \mathrm{FVC}<70 \%$ and $\mathrm{p}=0.003$ for $\mathrm{FEV}_{1} /$ FVC $<$ LLN). In contrast, no consistent relations of L1-ORF1p to lung function and airflow limitation were observed among never-smokers. Interaction terms between L1-ORF1p and smoking status were significant for $\mathrm{FEV}_{1}(\mathrm{p}<0.001)$ and FVC $(\mathrm{p}<0.001)$, and borderline for $\mathrm{FEV}_{1} / \mathrm{FVC}(\mathrm{p}=0.09)$.

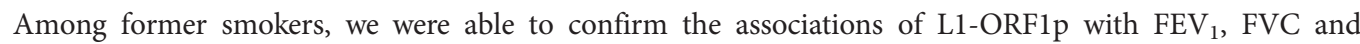
airflow limitation after further adjustment for active asthma and after restricting analyses to participants with no active asthma (data not shown). In addition, among former smokers, participants in the highest quartile of L1-ORF1p had mean $\mathrm{FEV}_{1}$ deficits of $18 \%(\mathrm{p}=0.002)$, FVC deficits of $14 \%(\mathrm{p}=0.009)$ and a 10 -fold increased risk for $\mathrm{FEV}_{1} / \mathrm{FVC}<70 \%(\mathrm{p}=0.053)$ as compared with participants in the lowest quartile.

The reasons why, in our study, serum L1-ORF1p was associated with lung function impairment only among former smokers are unclear at this time, but these effects are unlikely to be due to previous pulmonary infections or conditions that may have led participants to quit smoking because we did not

TABLE 1 Estimates of the association of 1-SD increase in serum L1-ORF1p with lung function indices and airflow limitation

\begin{tabular}{|c|c|c|c|c|c|c|c|c|c|c|}
\hline & \multicolumn{2}{|c|}{$\mathrm{FEV}_{1} \%$ predicted } & \multicolumn{2}{|c|}{ FVC $\%$ predicted } & \multicolumn{2}{|c|}{$\mathrm{FEV}_{1} / \mathrm{FVC}$} & \multicolumn{4}{|c|}{ Airflow limitation } \\
\hline & $\begin{array}{l}\text { Adjusted } \\
\text { coefficient } \\
(95 \% \mathrm{Cl})\end{array}$ & $\mathrm{p}$-value & $\begin{array}{l}\text { Adjusted } \\
\text { coefficient } \\
(95 \% \mathrm{CI})\end{array}$ & p-value & $\begin{array}{l}\text { Adjusted } \\
\text { coefficient } \\
(95 \% \mathrm{Cl})\end{array}$ & p-value & $\begin{array}{c}\text { Adjusted } \\
\text { OR } \\
(95 \% \mathrm{CI})\end{array}$ & $\mathrm{p}$-value & $\begin{array}{c}\text { Adjusted } \\
\text { OR } \\
(95 \% \mathrm{CI})\end{array}$ & p-value \\
\hline All subjects ${ }^{\#}(n=418)$ & $\begin{array}{c}-1.50 \\
(-3.28,0.29)\end{array}$ & 0.100 & $\begin{array}{c}-0.58 \\
(-2.25,1.09)\end{array}$ & 0.499 & $\begin{array}{c}-0.83 \\
(-1.75,0.08)\end{array}$ & 0.074 & $\begin{array}{c}1.26 \\
(0.93,1.73)\end{array}$ & 0.140 & $\begin{array}{c}1.36 \\
(1.00,1.85)\end{array}$ & 0.053 \\
\hline $\begin{array}{l}\text { Ever-smokers }^{\#} \\
\quad(n=242)\end{array}$ & $\begin{array}{c}-3.36 \\
(-5.65,-1.07)\end{array}$ & 0.004 & $\begin{array}{c}-2.40 \\
(-4.47,-0.33)\end{array}$ & 0.023 & $\begin{array}{c}-1.33 \\
(-2.49,-0.18)\end{array}$ & 0.024 & $\begin{array}{c}1.31 \\
(0.93,1.84)\end{array}$ & 0.124 & $\begin{array}{c}1.40 \\
(1.01,1.96)\end{array}$ & 0.046 \\
\hline $\begin{array}{l}\text { Former smokers }{ }^{+} \\
\qquad(n=123)\end{array}$ & $\begin{array}{c}-7.09 \\
(-10.66,-3.51)\end{array}$ & $<0.001$ & $\begin{array}{c}-5.50 \\
(-8.87,-2.13)\end{array}$ & 0.001 & $\begin{array}{c}-2.31 \\
(-4.04,-0.58)\end{array}$ & 0.009 & $\begin{array}{c}1.91 \\
(1.14,3.19)\end{array}$ & 0.014 & $\begin{array}{c}2.12 \\
(1.29,3.47)\end{array}$ & 0.003 \\
\hline $\begin{array}{l}\text { Current smokers }{ }^{+} \\
{[(n=119]}\end{array}$ & $\begin{array}{c}0.21 \\
(-2.51,2.93)\end{array}$ & 0.880 & $\begin{array}{c}0.92 \\
(-1.45,3.30)\end{array}$ & 0.446 & $\begin{array}{c}-0.08 \\
(-1.67,1.51)\end{array}$ & 0.919 & $\begin{array}{c}1.00 \\
(0.59,1.70)\end{array}$ & 0.991 & $\begin{array}{c}1.15 \\
(0.71,1.85)\end{array}$ & 0.571 \\
\hline
\end{tabular}

Body mass index (BMI) information was missing for nine participants (two never-, three former and four current smokers). Airflow limitation was present among 67 and 56 participants when defined by forced expiratory volume in $1 \mathrm{~s}\left(\mathrm{FEV}_{1}\right) /$ forced vital capacity (FVC) <70\% and below the lower limit of normal (LLN), respectively. " : models adjusted for sex, age, BMI, smoking status and pack-years; ${ }^{\text {": }}$ models adjusted for sex, age and $\mathrm{BMI}^{+}{ }^{+}$: models adjusted for sex, age, BMI and pack-years. 
observe differences in serum L1-ORF1p by history of pneumonia and/or chronic bronchitis either in the total population or among smokers (data not shown). Chemicals present in tobacco smoke, such a benzopyrene, reactivate LINE-1 [10] and persistent upregulation of L1-ORFs after smoking cessation may be an indicator of long-term susceptibility to cigarette smoking-induced genomic injury. Indeed, smoking cessation does not resolve airway and systemic inflammation in a proportion of former smokers who remain at increased risk of inception and progression of COPD for years after quitting [11, 12]. In this context, two observations are noteworthy. First, because the distribution by sex was strongly associated with smoking status in our study (the proportion of males was 35\%,57\% and $16 \%$ among current, former and never-smokers, respectively), we cannot exclude that these effect modifications are related to sex instead of (or in addition to) smoking status itself. Second, in our study, L1-ORF1p effects in former smokers diverged mainly from those of never-smokers, and significant associations between L1-ORF1p and lung function were also present among ever-smokers (i.e. former and current smokers combined). Thus, larger studies will be required to determine conclusively the interrelationship between sex and smoking status in modifying L1-ORF1p effects on lung function and COPD. Because of the modest effect magnitude of some of the associations and the relatively small sample size of some subgroup analyses, replication studies are also warranted to test the generalisability of results. The value of measuring L1-ORF1p in serum versus other biospecimens in lung disease remains to be determined, as are the possible effects of time of collection, processing and storing of blood samples. Interestingly, we found stronger L1-ORF1p associations with $\mathrm{FEV}_{1}$ than $\mathrm{FVC}$, resulting in consistent effects on $\mathrm{FEV}_{1} / \mathrm{FVC}$ and risk for airflow limitation, an observation that is in line with the stronger effects of cigarette smoking on airway obstruction than spirometric restriction [13].

In conclusion, we observed higher circulating levels of L1-ORF1p to be associated with lower lung function levels and increased risk for airflow limitation among former smokers. However, before stratification of our population sample by smoking status, we did not find an association between serum L1-ORF1p and COPD. Additional studies are required to evaluate the possible role of LINE-1 in smoking-related airflow limitation.

Stefano Guerra ${ }^{1,2,3}$, Monica M. Vasquez ${ }^{1}$, Pasano Bojang Jr ${ }^{2}$, Irma N. Ramos ${ }^{4}$, Duane L. Sherrill ${ }^{1}$, Fernando D. Martinez ${ }^{1}$, Marilyn Halonen ${ }^{1,5}$ and Kenneth S. Ramos ${ }^{1,2,6}$

${ }^{1}$ Asthma and Airway Disease Research Center, University of Arizona, Tucson, AZ, USA. ${ }^{2}$ Division of Pulmonary, Allergy, Critical Care and Sleep Medicine, University of Arizona College of Medicine, Tucson, AZ, USA. ${ }^{3}$ ISGlobal, Barcelona, Spain. ${ }^{4}$ Dept of Promotion Health Sciences, University of Arizona Mel and Enid Zuckerman College of Public Health, Tucson, AZ, USA. ${ }^{5}$ Dept of Pharmacology, University of Arizona College of Medicine, Tucson, AZ, USA. ${ }^{6}$ Institute of Biosciences and Technology, Texas A\&M University, Houston, TX, USA.

Correspondence: Stefano Guerra, Asthma and Airway Disease Research Center, University of Arizona, Tucson, AZ 85719, USA. E-mail: stefano@email.arizona.edu

Kenneth S. Ramos, Institute of Biosciences and Technology, Texas A\&M University, Houston, TX 77030, USA. E-mail: kramos@tamu.edu

Received: 17 Dec 2018 | Accepted after revision: 2 Sept 2019

Conflict of interest: S. Guerra reports grants from the NIH during the conduct of the study. M.M. Vasquez has nothing to disclose. P. Bojang Jr has patent WO2017172839A1 (Use of biomarkers associated with LINE-1) issued. I.N. Ramos has nothing to disclose. D.L. Sherrill has nothing to disclose. F.D. Martinez reports grants from the National Institutes of Health (NIH)/National Heart, Lung and Blood Institute (HL139054, HL056177, HL132523, HL091889, HL130045 and HL098112), NIH/National Institute of Environmental Health Sciences (ES006694), NIH/National Institute of Allergy and Infectious Diseases (AI126694), NIH/Office of Director (OD023282) and Johnson \&amp; Johnson (UA009253-0001), and personal fees for consultancy from Copeval and Commense Inc., outside the submitted work. M. Halonen reports grants from the National Institutes of Health during the conduct of the study. K.S. Ramos reports grants from the National Institutes of Health during the conduct of the study. He holds patent W02017172839A1 (Use of biomarkers associated with LINE-1) and patent 2019 62/787444 (Systems and methods for characterizing and treating disease).

Support statement: This study was partially funded by HL107188 and HL095021 from the National Heart, Lung, and Blood Institute, and a University of Arizona Health Sciences and GURI Award. Funding information for this article has been deposited with the Crossref Funder Registry.

\section{References}

1 Ramos KS, Teneng I, Montoya-Durango DE, et al. The intersection of genetics and epigenetics: reactivation of mammalian LINE-1 retrotransposons by environmental injury. In: Jirtle RL, Tyson FL, eds. Environmental Epigenomics in Health and Disease: Epigenetics and Disease Origins. Heidelberg, Springer, 2013; pp. 127-160. 
Bojang P Jr, Ramos KS. Epigenetic reactivation of LINE-1 retrotransposon disrupts NuRD corepressor functions and induces oncogenic transformation in human bronchial epithelial cells. Mol Oncol 2018; 12: 1342-1357.

Reyes-Reyes EM, Aispuro I, Tavera-Garcia MA, et al. LINE-1 couples EMT programming with acquisition of oncogenic phenotypes in human bronchial epithelial cells. Oncotarget 2017; 8: 103828-103842.

Imperatori A, Sahnane N, Rotolo N, et al. LINE-1 hypomethylation is associated to specific clinico-pathological features in Stage I non-small cell lung cancer. Lung Cancer 2017; 108: 83-89.

5 Lange NE, Sordillo J, Tarantini L, et al. Alu and LINE-1 methylation and lung function in the normative ageing study. BMJ Open 2012; 2: e001231.

6 Lebowitz MD, Knudson RJ, Burrows B. Tucson epidemiologic study of obstructive lung diseases. I: Methodology and prevalence of disease. Am J Epidemiol 1975; 102: 137-152.

7 Knudson RJ, Slatin RC, Lebowitz MD, et al. The maximal expiratory flow-volume curve. Normal standards, variability, and effects of age. Am Rev Respir Dis 1976; 113: 587-600.

8 Knudson RJ, Lebowitz MD, Holberg CJ, et al. Changes in the normal maximal expiratory flow-volume curve with growth and aging. Am Rev Respir Dis 1983; 127: 725-734.

9 Pellegrino R, Viegi G, Brusasco V, et al. Interpretative strategies for lung function tests. Eur Respir J 2005; 26: 948-968.

10 Reyes-Reyes EM, Ramos IN, Tavera-Garcia MA, et al. The aryl hydrocarbon receptor agonist benzo(a)pyrene reactivates LINE-1 in HepG2 cells through canonical TGF- $\beta 1$ signaling: implications in hepatocellular carcinogenesis. Am J Cancer Res 2016; 6: 1066-1077.

11 Hogg JC. Why does airway inflammation persist after the smoking stops? Thorax 2006; 61: 96-97.

12 Miller M, Cho JY, Pham A, et al. Persistent airway inflammation and emphysema progression on CT scan in ex-smokers observed for 4 years. Chest 2011; 139: 1380-1387.

13 Guerra S, Sherrill DL, Venker C, et al. Morbidity and mortality associated with the restrictive spirometric pattern: a longitudinal study. Thorax 2010; 65: 499-504. 